CORRECTION

\title{
Correction: Genistein downregulates onco-miR-1260b and upregulates sFRP1 and Smad4 via demethylation and histone modification in prostate cancer cells
}

H Hirata ${ }^{1}$, Y Hinoda ${ }^{2}$, V Shahryari ${ }^{1}$, G Deng ${ }^{1}$, Y Tanaka ${ }^{1}$, Z L Tabatabai ${ }^{3}$ and R Dahiya ${ }^{1}$

British Journal of Cancer (2018) 119:388; https://doi.org/10.1038/s41416-018-0146-2

Correction to: British Journal of Cancer 110, 1645-1654 (2014); https://doi.org/10.1038/bjc.2014.48; published online 6 February 2014

The authors report that there is a mistake in the representative picture of Fig. 4D (top row: PC3-miR1260b inh-0h) in the original version. The correct version of Fig. 4 with the original pictures for both PC3 miR-NC inh-Oh and PC3-miR1260b inh-0h are provided below. a

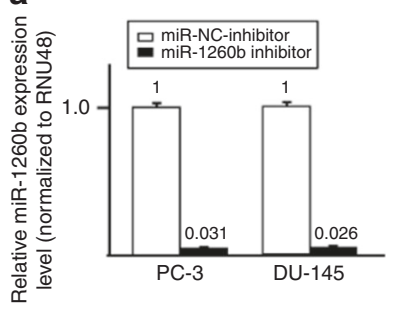

b

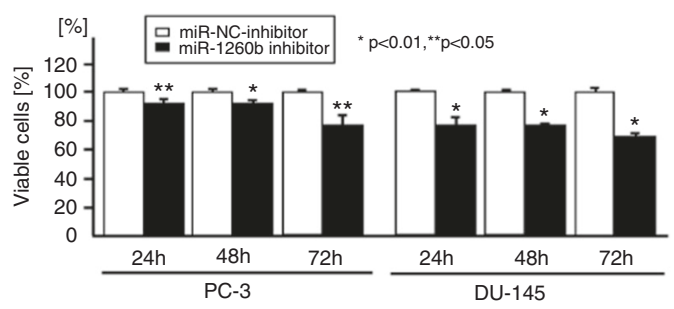

f

e
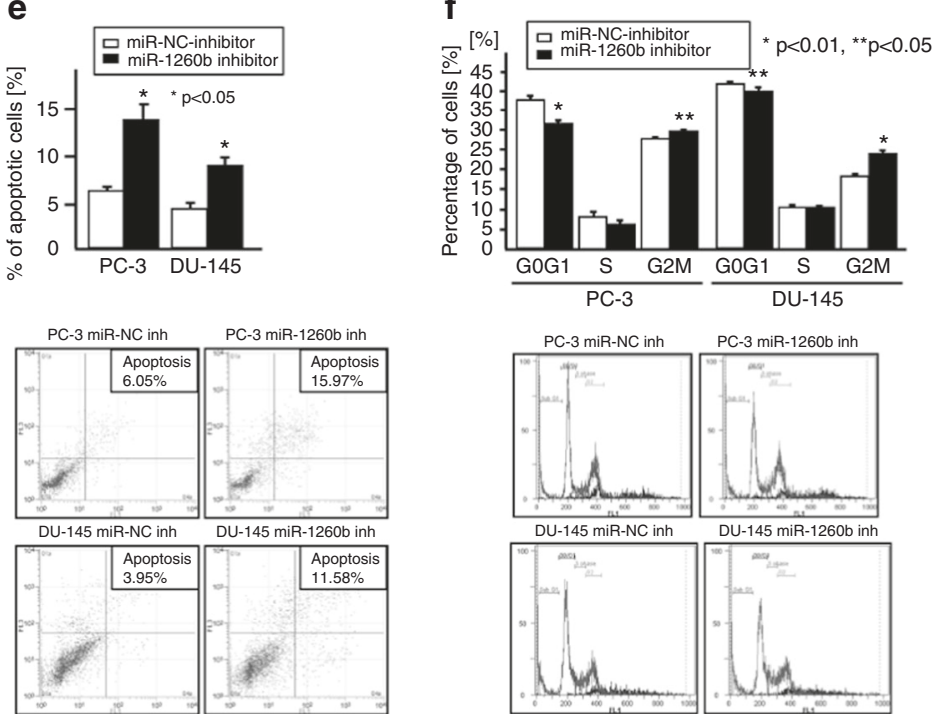

C
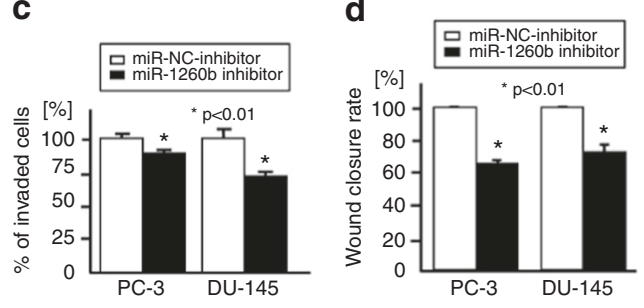

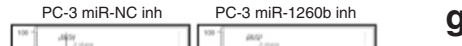

g

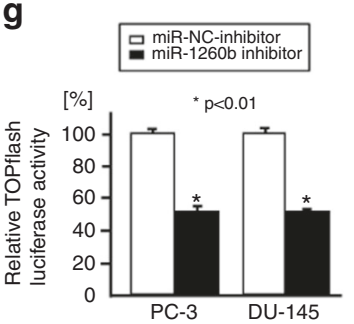

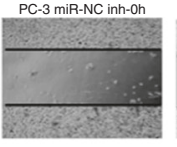
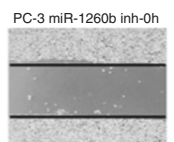

PC-3 miR-NC inh-17h

PC-3 miR-1260b inh-17h
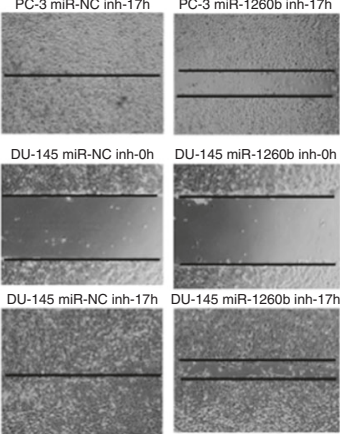

Fig. 4 Effect of miR-1260b knockdown on prostate cancer cells (PC-3, DU-145). Two prostate cancer cell lines (PC-3 and DU-145) were transiently transfected with either miR-1260b inhibitor or miR-negative control (miR-NC inhibitor). a Relative miR-1260b expression (miR-NC inhibitor or miR-1260b inhibitor transfected PC cells), b cell viability assay (miR-NC inhibitor or miR-1260b inhibitor transfected PC cells), c invasion assay, $\mathbf{d}$ wound healing assay (16-17 h). e Apoptosis assay, f cell cycle analysis, $\mathbf{g}$ TCF reporter assay. Error bars represent \pm s.d

${ }^{1}$ Department of Urology, San Francisco Veterans Affairs Medical Center and University of California at San Francisco, San Francisco, CA, USA; ${ }^{2}$ Department of Oncology and Laboratory Medicine, Yamaguchi University Graduate School of Medicine, Yamaguchi, Japan and ${ }^{3}$ Department of Pathology, San Francisco Veterans Affairs Medical Center and University of California at San Francisco, San Francisco, CA, USA

Correspondence: R Dahiya (rdahiya@urology.ucsf.edu)

Published online: 22 June 2018 